\title{
Histopathology of Endometrial Biopsies in Cases of Abnormal Uterine Bleeding- A Four Year Study
}

\author{
Authors \\ Dr Amruta Padhye ${ }^{1}$, Dr Urshlla Kaul ${ }^{2}$, Dr Reeta Dhar ${ }^{3}$ \\ ${ }^{1,2}$ PG student, Department of Pathology, MGM Medical College, Kamothe, Navi Mumbai \\ ${ }^{3}$ Head of Department, Department of Pathology, MGM Medical College, Kamothe, Navi Mumbai
}

\begin{abstract}
Background: Abnormal uterine bleeding $(A U B)$ is the bleeding pattern that differs in frequency, duration and amount from a pattern observed during a normal menstrual cycle or after menopause and is caused by a variety of disorders.
\end{abstract}

Materials and Methods: This is an observational study conducted at the department of Pathology at MGM Hospital, Navi Mumbai. A total number of 402 endometrial curettage specimens were obtained and studied over a period of 4 years from January 2013 till December 2016.

Objectives: The objective of our study was to evaluate the different histopathological patterns in the dilatation and curettage samples of females presenting with abnormal uterine bleeding.

Result and Conclusion: In our study, proliferative phase endometrium and hyperplasia without atypia were most common in the reproductive age group.

Keywords: abnormal uterine bleeding, endometrial hyperplasia, proliferative endometrium.

\section{Introduction}

Abnormal uterine bleeding (AUB) is defined as the bleeding pattern that differs in frequency, duration and amount from a pattern observed during a normal menstrual cycle or after menopause ${ }^{[1]}$. It is caused by a variety of systemic diseases such as anovulation, fibroids, polyps, adenomyosis and endometrial causes like endometritis, hyperplasia, disordered proliferative endometrium, cyclical endometrium, polyps and malignancy, endocrine disorders and pregnancy. The most common presentations are menorrhagia, polymenorrhoea, metrorrhagia, and intermenstrual bleeding. Dilatation and Curettage is the mainstay of endometrial sampling and is a safe and effective diagnostic step in evaluation of abnormal uterine bleeding. ${ }^{[2]}$ Histopathological examination of these endometrial biopsies and curettings is considered the gold standard for diagnosis of the etiology of AUB ${ }^{[1]}$.

\section{Materials and Methods}

This observational retrospective-prospective study was conducted in the department of Pathology of a tertiary hospital. A total of 402 patients presenting with abnormal uterine bleeding over a period of 4 years between January 2013 till December 2016 and who underwent $\mathrm{D} \& \mathrm{C}$ were included in the study. The age group of the patients presenting with AUB was from 18 to 75 years. The causes of AUB in this study included endometritis, endometrial hyperplasia, polyp, proliferative and secretory phases of 
endometrium, disordered proliferative and atrophic endometrium and endometrial carcinoma. Patients with bleeding disorders, cervical or vaginal pathology, leiomyoma, pregnancy and inadequate endometrial samples sent for histopathology were excluded. Relevant clinical data regarding age, pattern and duration of abnormal bleeding, menstrual history and gynaecological examination findings were obtained from case records from Medical Records Department.

\section{Results}

A total of 402 endometrial curettage specimens were obtained and studied. The patients' age was ranged from 18 to 75 years and most of the curettages were seen in the age group of 46-50 years. The commonest pathology observed in the study was endometrial hyperplasia in 121 (30.09\%) patients, followed by proliferative endometrium seen in $87(21.64 \%)$ patients and secretory endometrium in $50(12.43 \%)$ patients.

Endometrial carcinoma was seen in $12(2.98 \%)$ cases.

\section{Discussion}

In our study the age of the patients presenting with AUB was from 18 to 75 years. Table 1 shows that the patients were divided in 3 age groups: 18-45 years (reproductive), 46-50 years (perimenopausal) and $\geq 51$ years (postmenopausal). A total of 175 (43.53\%) patients presenting with AUB were seen in the perimenopausal age group (45-50 years). Our study and other studies have found a maximum incidence of AUB in the perimenopausal age group. [3-6] followed by $168(41.80 \%)$ patients in the reproductive age group (18-45 years) and 59 $(14.67 \%)$ in the postmenopausal age group ( $\geq 51$ years).

Table 1: Age distribution of patients

\begin{tabular}{|l|c|c|}
\hline Age Group (Years) & Total & Percentage \\
\hline $18-45$ & 168 & 41.80 \\
\hline $46-50$ & 175 & 43.53 \\
\hline$\geqslant 51$ & 59 & 14.67 \\
\hline Total & 402 & 100 \\
\hline
\end{tabular}

Table 2 shows the histopathological examination of the endometrium and its various histological patterns in different age groups.

In our study, proliferative phase endometrium and hyperplasia without atypia were most common in the reproductive age group making $48(28.57 \%)$ and $35(20.83 \%)$ cases respectively followed by endometrial polyp seen in $29(17.26 \%)$ cases. In the menopausal age group, the most common cause of AUB was again hyperplasia without atypia seen in $69(39.42 \%)$ cases followed by proliferative phase endometrium in $31(17.71 \%)$ and endometritis observed in $24(13.71 \%)$ patients. Endometrial carcinoma was observed to be most common in the menopausal age group and was seen in $9(15.25 \%)$ cases.

Table 2: Histopathological diagnosis of different age groups

\begin{tabular}{|l|c|c|c|c|c|}
\hline \multirow{2}{*}{$\begin{array}{l}\text { Histopathological } \\
\text { Patterns }\end{array}$} & \multicolumn{3}{|c|}{ Age Group (Years) } & \multirow{2}{*}{ Total } & \multirow{2}{*}{ Percentage } \\
\cline { 2 - 5 } & $\begin{array}{c}18- \\
45\end{array}$ & $46-50$ & $\begin{array}{c}\geqslant \\
51\end{array}$ & & \\
\hline Proliferative & 48 & 31 & 8 & 87 & 21.64 \\
\hline Secretory & 28 & 16 & 6 & 50 & 12.43 \\
\hline Atrophic & - & 2 & 7 & 9 & 2.23 \\
\hline Endometrial Polyp & 29 & 7 & 5 & 41 & 10.2 \\
\hline Endometritis Without & 17 & 24 & 6 & 47 & 11.7 \\
\hline Disordered Proliferation & 11 & 19 & 5 & 35 & 8.70 \\
\hline $\begin{array}{l}\text { Hyperplasia } \\
\text { Atypia }\end{array}$ & - & 69 & 7 & 111 & 27.61 \\
\hline $\begin{array}{l}\text { Hyperplasia } \\
\text { Atypia }\end{array}$ & - & 3 & 9 & 12 & 2.90 \\
\hline Endometrial Carcinoma & 168 & 175 & 59 & 402 & 100 \\
\hline Total & & & & & \\
\hline
\end{tabular}

Endometrial hyperplasia was the most common histological pattern observed in our study and was seen in 121 cases $(30.09 \%)$. Studies conducted by Riaz et al have reported a similar incidence with $26 \%$ respectively ${ }^{[7]}$.

Endometrial hyperplasia is a precursor of endometrial carcinoma ${ }^{[3]}$ and the overall risk of progression of hyperplasia to cancer is $5-10 \% .^{[2]}$ Such patients should be followed up regularly.

Proliferative and secretory phase - Predominant number of patients in the age group 18-50 years showed these normal physiological changes. Proliferative endometrium was the second most common pattern observed in this study and was seen in 87 out of $402(21.64 \%)$ patients followed by secretory endometrium in $50(12.43 \%)$. A similar 
incidence of secretory pattern $(16.6 \%)$ was noted by Bhosle et al. ${ }^{[4]}$

\section{Disordered proliferative endometrium resembles} normal proliferative tissue consisting of glands lined by cytologically bland, pseudostratified, proliferative, mitotically active epithelium and in having a normal ratio of glands to stroma and it occurs predominantly in perimenopausal women. In our study, this pattern was observed in $35(8.70 \%)$ cases which was similar to the study by Gopalan U et al. ${ }^{(8)}$ Atrophic endometrium is the most one of the most common causes of bleeding in postmenopausal stage. ${ }^{\text {9] }}$ Thin walled veins, superficial to the expanding cystic glands, make the vessels vulnerable to injury and lead to excessive uterine bleeding. ${ }^{[10]}$ In our study, $15.25 \%$ of post menopausal women showed atrophic endometrium on dilatation and curettage.A previous stud done by Mahapatra et al ${ }^{[11]}$ showed similar findings.

Endometrial carcinoma The malignant conditions observed in this study included 12 cases of endometrial carcinoma and had an incidence of $2.98 \%$. The predominant type of observed was endometrioid type which constituted 9 cases. Six cases were classical endometrioid adenocarcinoma and villoglandular variants and three were endometrioid carcinoma with squamous differentiation. Tiwari et al ${ }^{[12]}$ showed a similar incidence of $5 \%$.

\section{Conclusion}

Abnormal uterine bleeding is a pathology which affects various age groups and the cause varies with different age groups. Endometrial biopsy is an important tool to diagnose different gynaecological conditions in patients and to detect pre-neoplastic lesions like hyperplasia with atypia or frank malignancy and thus help the clinicians to plan therapy for successful management of AUB.

\section{Acknowledgements: None}

\section{References}

1. Puneet Kaur et al. A two year histopathological study of endometrial biopsies in a teaching hospital....Indian
Journal of Pathology and Oncology, JulySeptember 2016;3(3);508-519

2. Sajitha, et al.: Endometrial pathology in AUB. CHRISMED Journal of Health and Research /Vol 1/Issue 2/Apr-Jun 2014

3. Doraiswami et al. Study of Endometrial Pathology The Journal of Obstetrics and Gynecology of India (July-August 2011) 61(4):426-430

4. Bhosle A, Fonseca M. Evaluation and histopathological correlation of abnormal uterine bleeding in perimenopausal women. Bombay Hosp J 2010;52:69-72.

5. Sinha $P$ et al. Pearls and pitfalls of endometrial curettage with that of hysterectomy in DUB. J Clin Diagn Res 2011;5:1199-202.

6. Azim $P$ et al. Evaluation of abnormal uterine bleeding on endometrial biopsies. Isra Med J 2011;3:84-8.

7. Riaz $\mathrm{S}$ et al. Endometrial pathology by endometrial curettage in menorrhagia in premenopausal age group.J Ayub Med Coll Abbottabad 2010;22:161-4.

8. Gopalan U et al. Int J Reprod Contracept Obstet Gynecol. 2017 Mar;6(3):824-828

9. Cornitescu FI et al. Clinical, histopathological and therapeutic considerations in non-neoplastic abnormal uterine bleeding in menopause transition. Rom J Morphol Embryol 2011;52:759-65.

10. Baral R, Pudasini S. Histopathological pattern of endometrial samples in abnormal uterine bleeding. J Path Nepal 2011;1:13-6.

11. Mahapatra M, Mishra P. Clinicopathological evaluation of abnormal uterine bleeding. J Health Res Rev 2015;2:45-9.

12. Tiwari A. et al. Histopathological study of endometrial biopsy specimens for abnormal uterine bleeding. J. Lumbini. Med. Coll. Vol 4, No 2, July-Dec 2016 